Research Paper

\title{
Antimicrobial activity of the essential oil of Tetradenia riparia (Hochst.) Codd. (Lamiaceae) against cariogenic bacteria
}

\author{
Nathalya Isabel de Melo ${ }^{1}$, Carlos Eduardo de Carvalho ${ }^{1}$, Letícia Fracarolli ${ }^{1}$, \\ Wilson Roberto Cunha ${ }^{1}$, Rodrigo Cassio Sola Veneziani ${ }^{1}$, \\ Carlos Henrique Gomes Martins ${ }^{1}$, Antônio Eduardo Miller Crotti ${ }^{1,2}$ \\ ${ }^{1}$ Núcleo de Pesquisas em Ciências Exatas e Tecnológicas, Universidade de Franca, Franca, SP, Brazil. \\ ${ }^{2}$ Faculdade de Filosofia, Ciências e Letras de Ribeirão Preto, Universidade de São Paulo, \\ Ribeirão Preto, SP, Brazil.
}

Submitted: August 1, 2014; Approved: October 30, 2014.

\begin{abstract}
In Brazilian folk medicine, Tetradenia riparia (Hochst.) Codd. (Lamiaceae) is used to treat toothaches and dental abscesses and diseases induced by worms, bacteria, or fungi. This paper aims to investigate the chemical composition and the antibacterial effects of the essential oil obtained from Tetradenia riparia leaves (TR-EO) grown in Southeastern Brazil against a representative panel of oral pathogens. We evaluated the antibacterial activity of TR-EO in terms of the minimal inhibitory concentration (MIC).We identified aromadendrene oxide (14.0\%), (E,E)-farnesol (13.6\%), dronabinol (12.5\%), and fenchone (6.2\%) as the major constituents of TR-EO. TR-EO displayed MIC values between 31.2 and $500 \mu \mathrm{g} / \mathrm{mL}$, with the lowest MIC value being obtained against Streptococcus mitis $(31.2 \mu \mathrm{g} / \mathrm{mL})$, S. mutans $(62.5 \mu \mathrm{g} / \mathrm{mL})$, S. sobrinus $(31.2 \mu \mathrm{g} / \mathrm{mL})$, and Lactobacillus casei $(62.5 \mu \mathrm{g} / \mathrm{mL})$. In time-kill experiments, TR-EO demonstrated bactericidal activity against $S$. mutans within the first $12 \mathrm{~h}$, resulting in a curve profile similar to that of chlorhexidine. These results revealed that the essential oil of Tetradenia riparia displays promising activity against most of the selected cariogenic bacteria, including Streptococcus mutans.
\end{abstract}

Key words: Streptococcus mutans, oral pathogens, cariogenic bacteria.

\section{Introduction}

Dental caries is a major public health concern that affects many countries worldwide. This pathology and other periodontal diseases are associated with acidogenic and aciduric bacteria that adhere to the tooth surface as a structurally and functionally organized biofilm (dental plaque) (Marsh, 2003; Marsh, 2006). The most efficient procedure to prevent caries is to remove the biofilm by brushing and flossing; however, most people fail to maintain a sufficient level of control through mechanical removal only (Barnett, 2006). Therefore, the use of oral products containing antimicrobial ingredients as a complementary measure has become necessary and has great value in regard to diminishing tooth surface biofilm (Furiga et al., 2008; Sharma et al., 2004). Currently, chlorhexidine is considered to be the anticariogenic gold standard and has received the approval of the American Dental Association Council on Dental Therapeutics. Nevertheless, the regular use of oral care products containing this chemical often incurs several side effects (Greenberg et al., 2008; More et al., 2008). As a result, the search for new potential chemotherapeutic agents that can be incorporated into dental products has escalated in recent years (Palombo, 2011).

Over the last decade, a number of papers have reported the antimicrobial potential of essential oils (EOs) extracted from plants against oral pathogens (Aguiar et al., 2013; Alviano et al., 2005; Botelho et al., 2007; Filoche et al., 2005; Iscan et al., 2002; Maggi et al., 2009). EOs consist of mixtures of a variety of lipid-soluble and volatile compounds, such as monoterpenes, sesquiterpenes, and

Send correspondence to A.E.M. Crotti. Departamento de Química, Faculdade de Filosofia, Ciências e Letras de Ribeirão Preto, Universidade de São Paulo, Av. Bandeirantes 3900, 14040-901, Ribeirão Preto, SP, Brazil. E-mail: millercrotti@ffclrp.usp.br. 
phenylpropanoids, that can easily diffuse across cell membranes, a major advantage with regard to interactions with intracellular targets (Edris, 2007). Additionally, synergistic interactions between the components of EOs are possible and beneficial for their activities (Dorman and Deans, 2000).

Tetradenia riparia (Hochst.) Codd. (Lamiaceae), commonly known in Brazil as "false myrrh", is an herbaceous and aromatic shrub that originated in South Africa; it was introduced as an exotic ornamental plant in Brazil (Gazim et al., 2010; Phillipson and Steyn, 2008). In folk medicine, this species is used to treat toothaches and dental abscesses, malaria, and diseases induced by worms, bacteria, or fungi, among others (Scott et al., 2004; Vanpuyvelde et al., 1988; Vlietinck et al., 1995). The essential oil from $T$. riparia leaves displays repellent (Omolo et al., 2004), insecticidal (Dunkel et al., 1990), ascaricidal (Peter and Deogracious, 2006), antimalarial (Campbell et al., 1997), and antinociceptive actions (Gazim et al., 2010). Recently, the antimicrobial activity of this oil against Candida albicans, Staphylococcus aureus, Bacillus subtilis, Escherichia coli, Pseudomonas aeruginosa, Enterococcus faecalis, Proteus mirabilis, Klebsiella pneumonia, and Salmonella enterica was reported (Gazim et al., 2010). However, despite its use in folk medicine to treat toothaches and dental abscesses, the effects of this essential oil against oral pathogens have not yet been investigated.

This paper reports the chemical composition and antimicrobial activity of the essential oil of $T$. riparia leaves (TR-EO) grown in Southeastern Brazil against a representative panel of cariogenic bacteria.

\section{Materials and Methods}

\section{Plant material}

Tetradenia riparia (Hochst.) Codd. (Lamiaceae) was collected at “Sítio 13 de Maio" (20²6’ S 47²7’ W, $977 \mathrm{~m}$ ) in February 2010 near Franca, State of São Paulo, Brazil and identified by Prof. Milton Groppo. A voucher specimen (SPFR12421) was deposited at the Herbarium of Departamento de Biologia, Faculdade de Filosofia, Ciências e Letras de Ribeirão Preto, Universidade de São Paulo, São Paulo, Brazil (Herbarium SPFR).

\section{Essential oil extraction, GC and GC-MS analysis}

Fresh leaves (300 g) were submitted to hydrodistillation in a Clevenger-type apparatus for $3 \mathrm{~h}$. To this end, $1,200 \mathrm{~g}$ of plant material was divided into three samples of $400 \mathrm{~g}$ each, and $500 \mathrm{~mL}$ of distilled water was added to each sample. After manual collection, traces of water remaining in the essential oil (EO) were removed using anhydrous sodium sulfate, which was followed by filtration. The EO was stored in an amber bottle and kept in the refrigerator at $4{ }^{\circ} \mathrm{C}$ until further analysis. The EO yield was calculated from the weight of fresh leaves and expressed as the average of triplicate analysis.

\section{GC-FID and GC-MS analyses}

TR-EO was analyzed by gas chromatography (GC) on a Hewlett-Packard G1530A 6890 gas chromatograph fitted with FID and a data-handling processor. An HP-5 (Hewlett-Packard, Palo Alto, CA, USA) fused-silica capillary column ( $30 \mathrm{~m}$ x $0.25 \mathrm{~mm}$ i.d.; $0.33 \mu \mathrm{m}$ film thickness) was employed. The operation conditions were as follows: column temperature programmed to rise from 60 to $240{ }^{\circ} \mathrm{C}$ at $3{ }^{\circ} \mathrm{C} / \mathrm{min}$ and then held at $240{ }^{\circ} \mathrm{C}$ for $5 \mathrm{~min}$; carrier gas $=\mathrm{H}_{2}$, at $1.0 \mathrm{~mL} / \mathrm{min}$; injection mode; injection volume, $0.1 \mu \mathrm{L}$ (split ratio of 1:10); and injector and detector temperatures $=240$ and $280^{\circ} \mathrm{C}$, respectively. Components relative concentrations were obtained by peak area normalization $(\%)$. The relative areas were the average of triplicate GC-FID analyses.

GC-MS analyses were carried out on a Shimadzu QP2010 Plus (Shimadzu Corporation, Kyoto, Japan) system equipped with an AOC-20i autosampler. The column was a Rtx-5MS (Restek Co., Bellefonte, PA, USA) fused silica capillary column ( $30 \mathrm{~m}$ x $0.25 \mathrm{~mm}$ i.d. $\mathrm{x} 0.25 \mu \mathrm{m}$ film thickness). Electron ionization mode occurred at $70 \mathrm{eV}$. Helium (99.999\%) was employed as the carrier gas at a constant flow of $1.0 \mathrm{~mL} / \mathrm{min}$. The injection volume was $0.1 \mu \mathrm{L}$ (split ratio of 1:10). The temperatures of the injector and the ion-source temperature were set at 240 and $280^{\circ} \mathrm{C}$, respectively. The oven temperature program was the same as the program used for GC. Mass spectra were taken with a scan interval of $0.5 \mathrm{~s}$, in the mass range from 40 to $600 \mathrm{Da}$. TR-EO components identification was based on their retention indices on an Rtx-5MS capillary column under the same operating conditions as in the case of $\mathrm{GC}$ relative to a homologous series of $n$-alkanes $\left(\mathrm{C}_{8}-\mathrm{C}_{24}\right)$; structures were computer-matched with the Wiley 7, NIST 08, and FFNSC 1.2 spectra libraries, and their fragmentation patterns were compared with literature data (Adams, 2007).Standard compounds available in our laboratory were also co-eluted with TR-EO to confirm the identity of some essential oil components.

\section{Bacterial strains and antimicrobial assays}

The TR-EO minimum inhibitory concentration (MIC) values were calculated by using the broth microdilution method in 96-well microplates (CLSI, 2009). The following standard strains from the ATCC were used: Streptococcus salivarius (ATCC 25975), Streptococcus sobrinus (ATCC 33478), Streptococcus mutans (ATCC 25175), Streptococcus mitis (ATCC 49456), Streptococcus sanguinis (ATCC 10556), and Lactobacillus casei (ATCC 11578). Individual 24-hour colonies from blood agar (Difco Labs, Detroit, Mich, USA) were suspended in $10.0 \mathrm{~mL}$ of tryptic soy broth (Difco). Standardization of each microorganism suspension was carried out using a 
spectrophotometer (Femto, São Paulo, Brazil) at a wavelength $(\lambda)$ of $625 \mathrm{~nm}$, to match the transmittance of 81 , equivalent to 0.5 on the McFarland scale $\left(1.5 \times 10^{8}\right.$ $\mathrm{cfu} / \mathrm{mL}$ ), followed by dilution to a final concentration of $5 \mathrm{x}$ $10^{5} \mathrm{cfu} / \mathrm{mL}$. The samples were dissolved in DMSO (Merck, Darmstadt, Germany) at $4 \mathrm{mg} / \mathrm{mL}$ and were then diluted in tryptic soy broth (Difco), to yield concentrations between 3.9 and $4000 \mu \mathrm{g} / \mathrm{mL}$. The final DMSO concentration was $5 \%(\mathrm{v} / \mathrm{v})$, and this solution was used as a negative control. One inoculated well was included, to control broth adequacy for organism growth. One non-inoculated well free of antimicrobial agents was also included, to ensure medium sterility. Two-fold serial dilutions of chlorhexidine dihydrochloride (CHD) (Sigma-Aldrich, St. Louis) were made in tryptic soy broth (Difco), to obtain concentrations ranging from 59.0 to $0.115 \mathrm{~g} / \mathrm{mL}$. These dilutions were used as positive controls. The microplates (96 well) were sealed with parafilm and incubated at $37^{\circ} \mathrm{C}$ for $24 \mathrm{~h}$. Before the addition of resazurin and the determination of the minimal bactericidal concentration (MBC), an aliquot of the inoculum was aseptically removed from each well presenting no apparent growth and then plated onto tryptic soy agar supplemented with $5 \%$ sheep blood. The plates were incubated as described above. After plating, $30 \mu \mathrm{L}$ of $0.02 \%$ resazurinin aqueous solution (Sigma, St. Louis, MO, USA) was poured into each microplate reservoir, to indicate microorganism viability (Porto et al., 2009). The minimal inhibitory concentration (MIC) was determined as the lowest EO concentration capable of inhibiting microorganism growth. Three replicates were made for each microorganism.

The determination of MBC values (the lowest EO concentration in which $99.99 \%$ or more of the initial inoculum was killed) and the TR-EO time-kill-assays were conducted against $S$. mutans only because it is considered one of the primary causative agents of dental caries (Chung et al., 2006). Time-kill assays were performed in triplicate on the basis of the methodology established by D'Arrigo and co-workers (D'Arrigo et al., 2010). Tubes containing TR-EO at final concentrations of 62.5, 125, and $187.5 \mu \mathrm{g} / \mathrm{mL}$ (respectively one, two, and three times the TR-EO minimum bactericidal concentration for S. mutans) were inoculated with the tested microorganism, which resulted in an initial bacterial density of $5 \times 10^{5} \mathrm{cfu} / \mathrm{mL}$, and then incubated at $37^{\circ} \mathrm{C}$. Samples were removed, to determine viable strains at $0,30 \mathrm{~min}, 6,12$, and $24 \mathrm{~h}$ after incubation, followed by dilution in sterile fresh medium when necessary. The diluted samples $(50 \mu \mathrm{L})$ were spread onto tryptic soy agar plate supplemented with $5 \%$ sheep blood, incubated at $37^{\circ} \mathrm{C}$, and counted after $48 \mathrm{~h}$. Time-kill curves were constructed by plotting $\log _{10} \mathrm{cfu} / \mathrm{mL}$ vs time. The assays were conducted in triplicate for each concentration and also for the positive (CHD, $0.92 \mu \mathrm{g} / \mathrm{mL}$ ) and negative controls (suspension of $S$. mutans without added TR-EO).

\section{Results}

We obtained the essential oil extracted from $T$. riparia leaves $(\mathrm{FV}-\mathrm{EO})$ in $1.09 \pm 0.15 \%$ yield $(\mathrm{w} / \mathrm{w})$. Table 1 depicts the chemical composition of TR-EO, as determined by GC-FID and GC-MS analyses. We identified a total of 37 compounds, with a predominance of oxygenated sesquiterpenes $(42.7 \%)$. We verified that aromadendrene oxide (1, 14.0\%), (E,E)-farnesol (2, 13.6\%), dronabinol (3, $12.5 \%)$, and fenchone $(4,6.3 \%)$ were the major constituents in TR-EO (Figure 1).

We investigated the antibacterial activity of TR-EO against the main cariogenic bacteria in terms of their minimum inhibitory concentrations (MIC) values compared with chlorhexidine dihydrochloride (CHD, positive control). Table 2 summarizes the obtained MIC values. TR-EO furnished MIC values ranging from 31.2 to $500 \mu \mathrm{g} / \mathrm{mL}$ against the main causative agents of dental caries. The lowest TR-EO MIC values were obtained against $S$. mitis

Table 1 - Chemical composition of the essential oil of Tetradeniariparia leaves (TR-EO).

\begin{tabular}{|c|c|c|c|c|c|}
\hline Compound & RT & $\mathrm{RI}_{\text {exp }}$ & $\mathrm{RI}_{\text {lit }}$ & RA \% & Identification \\
\hline$\alpha$-pinene & 6.53 & 938 & 939 & $\mathrm{t}$ & RL, MS, Co \\
\hline Camphene & 6.95 & 954 & 953 & 0.6 & RL, MS \\
\hline Sabinene & 7.62 & 978 & 976 & 0.8 & RL, MS \\
\hline$\beta$-pinene & 7.75 & 983 & 980 & 0.5 & RL, MS, Co \\
\hline Limonene & 9.35 & 1033 & 1031 & 0.9 & RL, MS, Co \\
\hline cis- $\beta$-ocimene & 9.60 & 1040 & 1043 & 0.5 & RL, MS \\
\hline Fenchone (4) & 11.51 & 1095 & 1094 & 6.3 & RL, MS, Co \\
\hline$\alpha$-fenchol & 12.44 & 1120 & 1104 & 0.7 & RL, MS \\
\hline Camphor & 13.64 & 1151 & 1143 & 2.0 & RL, MS, Co \\
\hline Borneol & 14.46 & 1173 & 1165 & 0.8 & RL, MS \\
\hline Terpinen-4-ol & 14.89 & 1184 & 1177 & 0.7 & RL, MS \\
\hline
\end{tabular}


Table 1 (cont.)

\begin{tabular}{|c|c|c|c|c|c|}
\hline Compound & RT & $\mathrm{RI}_{\exp }$ & $\mathrm{RI}_{\text {lit }}$ & RA \% & Identification \\
\hline$\alpha$-terpineol & 15.41 & 1197 & 1189 & 1.0 & RL, MS \\
\hline Unknown & 21.12 & 1372 & - & 0.4 & \\
\hline Unknown & 22.63 & 1391 & - & 0.8 & \\
\hline$\alpha$-copaene & 23.25 & 1399 & 1376 & 0.8 & RL, MS \\
\hline$\beta$-elemene & 23.94 & 1416 & 1391 & 1.5 & $\mathrm{RL}, \mathrm{MS}$ \\
\hline$\alpha$-gurjunene & 24.33 & 1426 & 1409 & 3.8 & RL, MS \\
\hline Trans-caryophyllene & 24.89 & 1441 & 1428 & 1.1 & RL, MS, Co \\
\hline$\alpha$-trans-bergamotene & 25.59 & 1460 & 1436 & 0.3 & RL, MS \\
\hline$\alpha$-humulene & 25.87 & 1467 & 1467 & 0.4 & $\mathrm{RL}, \mathrm{MS}, \mathrm{Co}$ \\
\hline Aromadendrene & 26.73 & 1490 & 1491 & 0.6 & $\mathrm{RL}, \mathrm{MS}$ \\
\hline Unknown & 26.90 & 1495 & - & 0.6 & \\
\hline Viridiflorene & 27.10 & 1500 & 1493 & 0.9 & RL, MS \\
\hline$E, E$ - $\alpha$-Farnesene & 27.22 & 1503 & 1508 & 2.7 & $\mathrm{RL}, \mathrm{MS}$ \\
\hline Bicyclogermacrene & 27.33 & 1507 & 1517 & 0.4 & RL, MS \\
\hline$\alpha$-muurolene & 27.59 & 1510 & 1510 & 0.5 & RL, MS \\
\hline Unknown & 27.79 & 1519 & - & 1.4 & \\
\hline 4-Methyl-2 6-di-tert-butylphenol & 27.91 & 1523 & 1519 & 0.4 & RL, MS, Co \\
\hline Cadinene & 28.05 & 1527 & 1513 & 2.1 & RL, MS \\
\hline Cis-nerolidol & 28.19 & 1531 & 1539 & 1.5 & RL, MS \\
\hline Unknown & 28.27 & 1540 & - & 0.6 & \\
\hline Germacrene-D-4-ol & 30.08 & 1582 & 1574 & 5.0 & $\mathrm{RL}, \mathrm{MS}$ \\
\hline Spathulenol & 30.16 & 1585 & 1576 & 0.1 & RL, MS \\
\hline Viridiflorol & 30.36 & 1590 & 1590 & 2.0 & RL, MS \\
\hline Unknown & 31.04 & 1610 & - & 0.8 & \\
\hline$\alpha$-cadinol & 32.41 & 1650 & 1653 & 2.6 & $\mathrm{RL}, \mathrm{MS}$ \\
\hline$\alpha$-Muurolol & 32.56 & 1655 & 1657 & 0.3 & $\mathrm{RL}, \mathrm{MS}$ \\
\hline Unknown & 32.71 & 1659 & - & 1.5 & \\
\hline t-cadinol & 32.89 & 1664 & 1660 & 5.1 & RL, MS \\
\hline Aromadendrene oxide (1) & 33.35 & 1672 & 1668 & 14.0 & $\mathrm{RL}, \mathrm{MS}$ \\
\hline$E, E$-Farnesol (2) & 34.18 & 1702 & 1706 & 13.6 & RL, MS \\
\hline 13-epimanoyl oxide & 4329 & 1996 & 2002 & 5.9 & RL, MS \\
\hline Cembrene $\mathrm{C}$ & 43.39 & 2000 & 2005 & 0.2 & RL, MS \\
\hline Unknown & 47.45 & 2138 & - & 1.2 & \\
\hline Dronabinol (3) & 48.88 & 2190 & 2202 & 12.5 & RL, MS \\
\hline Unknown & 53.18 & 2353 & - & 1.0 & \\
\hline Total & & & & 99.9 & \\
\hline Monoterpene hydrocarbons & 3.3 & & & & \\
\hline Oxygenated monoterpenes & 11.5 & & & & \\
\hline Sesquiterpene hydrocarbons & 15.1 & & & & \\
\hline Oxygenated sesquiterpenes & 42.7 & & & & \\
\hline Others & 19.0 & & & & \\
\hline Not identified & 8.3 & & & & \\
\hline
\end{tabular}

$\mathrm{RI}_{\text {exp }}$ : Retention index determined relative to $n$-alkanes $\left(\mathrm{C}_{8}-\mathrm{C}_{20}\right)$ on the Rtx-5MS column. b) $\mathrm{RI}_{\mathrm{lit}}$ : Retention index from the literature (Adams, 2007). c) Calculated from the peak area relative to the total peak area. d) Compound identification: RL, comparison of the RI with those of the literature (Adams, 2007); RA: relative area (peak area relative to the total peak area in the GC-FID chromatogram), average of three replicates; MS, comparison of the mass spectra with those of the Wiley 7, NIST 08, and FFNSC 1.2 spectral libraries as well as with those of literature (Adams, 2007); Co: co-elution with standard compounds available in our laboratory; t: relative area lower than $0.1 \%$. 


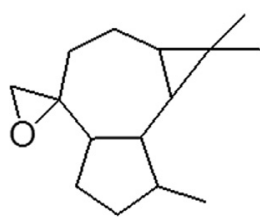

1<smiles>CC1=CC2c3c(O)cc(C(C)(C)C)cc3OC(C)(C)C2CC1</smiles>

3

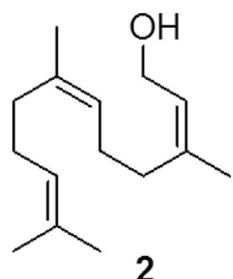

2

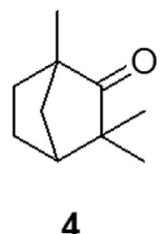

4
Figure 1 - Chemical structures aromadendrene oxide (1), $(E, E)$-farnesol (2), dronabinol (3), and fenchone (4).

$(31.2 \mu \mathrm{g} / \mathrm{mL}), \quad$ S. mutans $(62.5 \mu \mathrm{g} / \mathrm{mL}), \quad$ L. casei $(62.5 \mu \mathrm{g} / \mathrm{mL})$, and S. sobrinus $(62.5 \mu \mathrm{g} / \mathrm{mL})$.

Analysis of Figure 2 revealed that (1) at its MBC (62.5 $\mu \mathrm{g} / \mathrm{mL})$, TR-EO exhibited a bactericidal effect against $S$. mutans, the main cariogenic bacteria, within the first $12 \mathrm{~h}$ and that (2) its action became more pronounced after this period. We also constructed time-kill curves using two and three times the MBC value (data not shown). However, we did not verify any significant differences between the periods, indicating that no dose-dependent response effects existed for TR-EO in the assays conditions $(\mathrm{p}<0.05)$. Moreover, the TR-EO and CHD time-kill curve profiles were very similar.

\section{Discussion}

Campbell and co-workers have previously investigated the in vitro antimalarial activity and the chemical composition of the essential oil from Tetradenia riparia
Table 2 - Minimum inhibitory concentration (MIC) values $(\mu \mathrm{g} / \mathrm{mL})$ of the essential oil of Tetradeniariparia (TR-EO) against selected cariogenic bacteria.

\begin{tabular}{lll}
\hline Tested bacteria & TR-EO & CHD \\
\hline Streptococcus mutans & 62.50 & 0.92 \\
Streptococcus mitis & 31.25 & 3.68 \\
Lactobacillus casei & 62.50 & 0.92 \\
Streptococcus sanguinis & 125.0 & 7.37 \\
Streptococcus sobrinus & 62.50 & 0.92 \\
Streptococcus salivarus & 125.0 & 0.92 \\
\hline
\end{tabular}

CHD: chlorhexidine dihydrochloride.

leaves collected in South Africa (Campbell et al., 1997), and they identified the monoterpenes $\alpha$-terpineol (22.6\%), fenchone (13.6\%), $\beta$-fenchyl alcohol (10.7\%), and perilla alcohol (6.0\%) as major constituents. However, Omolo and co-workers identified fenchone $(64.8 \%)$ and limonene $(2.0 \%)$ as the main constituents of the repellent essential oil of T. riparia collected in Kenya (Omolo et al., 2004). More recently, Gazim and co-workers investigated the seasonal variation in the chemical composition and the antimicrobial activity of the essential oil from $T$. riparia leaves collected in Southern Brazil (Gazim et al., 2010) and verified that the most prevalent compounds in different seasons were the monoterpene fenchone; the sesquiterpenes 14-hydroxy-9epi-caryophyllene, cis-muurolol-5-en-4- $\alpha$-ol, and $\alpha$-cadinol; and the diterpene calyculone. In the present study, we also detected fenchone and aromadendrene oxide in the essential oil of T. riparia leaves (Gazim et al., 2010), but this is the first time that the presence of $(E, E)$-farnesol and dronabinol in this essential oil (Table 1) has been reported.

According to Rios and Recio (Rios and Recio, 2005) and Gibbons (Gibbons, 2004), EOs with MIC values higher than $1 \mathrm{mg} / \mathrm{mL}$ can be considered poorly active. However, EOs with MIC values below $100 \mu \mathrm{g} / \mathrm{mL}$ are interesting and

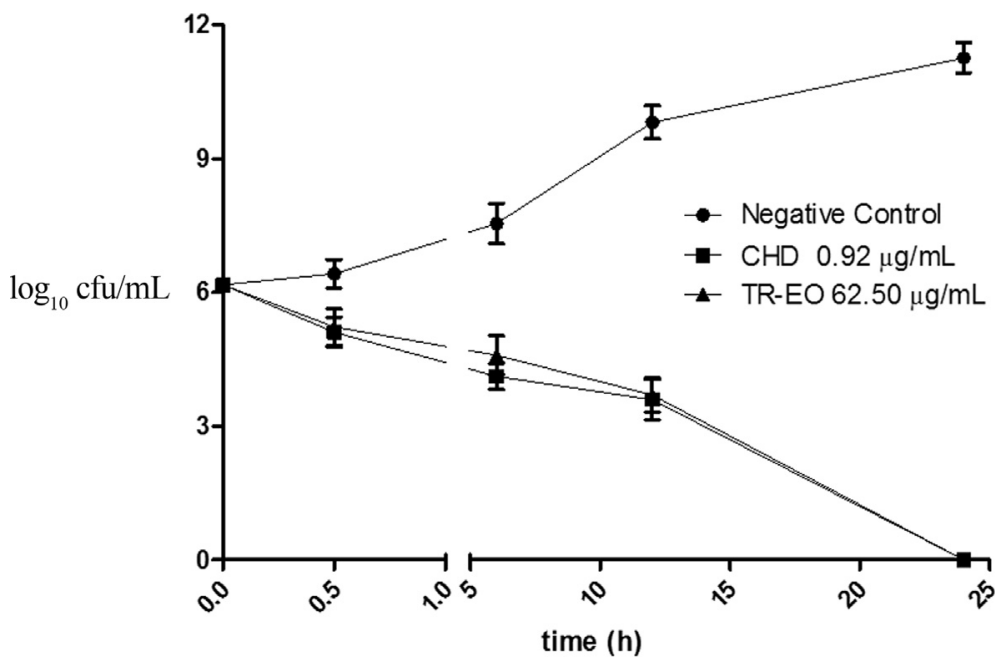

Figure 2 - Time-kill curve for the essential oil of T. riparia (TR-EO) against $S$. mutans $\left(5 \times 10^{5} \mathrm{cfu} / \mathrm{mL}\right)$. CHD: chlorhexidine. 
very promising in the search for new antimicrobial agents. On the basis of these criteria and the data presented in Table 2, TR-EO MIC values ranged from 31.2 to $500 \mu \mathrm{g} / \mathrm{mL}$ against the main causative agents of dental caries. Among all of the tested bacteria, TR-EO gave one of the lowest MIC values against $S$. mutans $(62.5 \mu \mathrm{g} / \mathrm{mL})$. This is a noteworthy result because very few natural compounds are known to inhibit this microorganism, which is one of the primary causative agents of dental caries (Porto et al., 2009; Saleem et al., 2010).

The very promising MIC value of TR-EO against the main bacterial strain that causes caries disease (S. mutans) prompted us to investigate further aspects of the antimicrobial activity of this natural product, such as its minimal bactericidal concentration (MBC) and time-kill curve (Figure 2). Analysis of Figure 1 revealed that at its $\mathrm{MBC}$, TR-EO exhibited its bactericidal effect within the first $12 \mathrm{~h}$, and its action became more pronounced after this period. It is noteworthy that the time-kill curve profiles of TR-EO and CHD were very similar.

In the literature, two possible action mechanisms have been proposed to explain the biological activities of essential oils. Both mechanisms are associated with the hydrophobicity of monoterpenes and sesquiterpenes, which often are the main chemicals thereof. The hydrophobicity of terpenoids would allow these compounds to permeate the cell membranes easily, hence causing parasites or microorganisms death by affecting their metabolic pathways or organelles (Knobloch et al., 1989). These essential oils themselves could interact with the parasite membrane and cause drastic physiological changes, leading to reduced membrane permeability and culminating in cell death (Bakkali et al., 2008; Knobloch et al., 1989). However, considering the large number of chemical constituents and synergistic or antagonistic interactions between these constituents, the essential oils could also act on cellular targets other than cell membranes, such as lipids and proteins (Bakkali et al., 2008; Borges et al., 2012). In this context, the antimicrobial activity of TR-EO against the selected oral pathogens might be related to the sesquiterpene $(E, E)$-farnesol, one of the major constituents of the essential oil. This compound has been reported to be active in vitro against $S$. sobrinus and $S$. mutans at concentrations of $14 \mu \mathrm{g} / \mathrm{mL}$ and $20 \mu \mathrm{g} / \mathrm{mL}$, respectively (Koo et al., 2002). The in vivo antimicrobial activity of $(E, E)$-farnesol in rodent teeth has also been evaluated by Koo and co-workers (Koo et al., 2002). The authors concluded that the topical application of this compound at a concentration of $1 \mathrm{mM}$ caused a decrease in biomass accumulation and prevented $S$. mutans adherence, thus confirming the potential of $(E, E)$-farnesol in caries prevention. However, the mechanism by which TR-EO displayed antimicrobial activity and the compounds responsible for the essential oil activity are not clear if we consider only the data obtained in this study.

\section{Conclusion}

In summary, the essential oil of $T$. riparia (TR-EO) displays promising antimicrobial activity against some cariogenic bacteria, including Streptococcus mutans, which is one of the main causative agents of dental caries. The TR-EO chemical composition is slightly different from that reported in previous studies. Taken together, our results suggest that this essential oil might be promising for the development of new oral care products. Further studies aiming to identify the active chemical constituents of TR-EO are underway.

\section{Acknowledgments}

The authors thank the Brazilian foundation FAPESP (Proc. 2007/54241-8) for financial support and thank CNPq for their fellowships. We are grateful to Prof. Dr. Milton Groppo for plant identification.

\section{References}

Adams R (2007) Identification of Essential Oils Components by Gas Chromatography/Mass Spectrometry. $4^{\text {th }}$ ed. Allured Publishing, Carol Stream, IL.

Aguiar GP, Carvalho CE, Dias HJ et al. (2013) Antimicrobial activity of selected essential oils against cariogenic bacteria. Nat Prod Res 27:1668-1672.

Alviano WS, Mendonça-Filho RR, Alviano DS et al. (2005) Antimicrobial activity of Croton cajucara Benth linaloolrich essential oil on artificial biofilms and planktonic microorganisms. Oral Microb Immun 20:101-105.

Bakkali F, Averbeck F, Averbeck D et al. (2008) Biological effects of essential oils - A review. Food Chem Toxicol 46:446-475.

Barnett ML (2006) The rationale for the daily use of an antimicrobial mouthrinse. J Am Dent Assoc 137:16S-21S.

Borges AR, Aires JR, Higino TM et al. (2012) Trypanocidal and cytotoxic activities of essential oils from medicinal plants of Northeast of Brazil. Exp Parasitol 132:123-128.

Botelho MA, Nogueira NA, Bastos GM et al. (2007) Antimicrobial activity of the essential oil from Lippia sidoides, carvacrol and thymol against oral pathogens. Braz J Med Biol Res 40:349-356.

Campbell WE, Gammon DW, Smith P et al. (1997) Composition and antimalarial activity in vitro of the essential oil of Tetradenia riparia. Planta Med 63:270-272.

Chung JY, Choo JH, Lee MH et al. (2006) Anticariogenic activity of macelignan isolated from Myristica fragrans (nutmeg) against Streptococcus mutans. Phytomedicine 13:261-266.

CLSI (2009) Susceptibility testing of aerobic bacteria. Approved standard, 8th ed. CLSI document M7-A8. NCCLS, Wayne, PA.

D'Arrigo M, Ginestra G, Mandalari G et al. (2010) Synergism and postantibiotic effect of tobramycin and Melaleuca alternifolia (tea tree) oil against Staphylococcus aureus and Escherichia coli. Phytomedicine 17:317-322.

Dorman HJD, Deans SG (2000) Antimicrobial agents from plants: antibacterial activity of plant volatile oils. J Appl Microb 88:308-316. 
Dunkel F, Weaver D, VanPuyvelde L et al. (1990) Population suppression effects of Rwandan medicinal plant, Tetradenia riparia (Hochst.) Codd (Lamiaceae) on stored grain and bean insects. Proc $5^{\text {th }}$ Int Wkg Conf Stored Prod Prot, p. 1609-1617.

Edris AE (2007) Pharmaceutical and therapeutic potentials of essential oils and their individual volatile constituents: a review. Phytother Res 21:308-323.

Filoche SK, Soma K, Sissons CH (2005) Antimicrobial effects of essential oils in combination with chlorhexidine digluconate. Oral Microb Immun 20:221-225.

Furiga A, Lonvaud-Funel A, Dorignac G et al. (2008) In vitro anti-bacterial and anti-adherence effects of natural polyphenolic compounds on oral bacteria. J Appl Microb 105:1470-1476.

Gazim ZC, Amorim ACL, Hovell AMC et al. (2010) Seasonal variation, chemical composition, and analgesic and antimicrobial activities of the essential oil from leaves of Tetradenia riparia (Hochst.) Codd in Southern Brazil. Molecules 15:5509-5524.

Gibbons S (2004) Anti-staphylococcal plant natural products. Nat Prod Rep 21:263-277.

Greenberg M, Dodds M, Tian M (2008) Naturally occurring phenolic antibacterial compounds show effectiveness against oral bacteria by a quantitative structure-activity relationship study. J Agr Food Chem 56:11151-11156.

Iscan G, Kirimer N, Kurkcuoglu M et al. (2002) Antimicrobial screening of Mentha piperita essential oils. J Agr Food Chem 50:3943-3946.

Knobloch K, Pauli A, Iberl B et al. (1989) Antibacterial and antifungal properties of essential oil components. J Essent Oil Res 1:118-119.

Koo H, Rosalen PL, Cury JA et al. (2002) Effects of compounds found in propolis on Streptococcus mutans growth and on glucosyltransferase activity. Antimicrob Agents Ch 46:1302-1309.

Maggi F, Bramucci M, Cecchini C et al. (2009) Composition and biological activity of essential oil of Achillea ligustica All. (Asteraceae) naturalized in central Italy: ideal candidate for anti-cariogenic formulations. Fitoterapia 80:313-319.

Marsh PD (2003) Plaque as a biofilm: pharmacological principles of drug delivery and action in the sub- and supragengival environment. Oral Dis 9:16-22.
Marsh PD (2006) Dental plaque as a biofilm and a microbial community - implications for health and disease. BMC Oral Health 6:S1-S14.

More G, Tshikalange TE, Lall N et al. (2008) Antimicrobial activity of medicinal plants against oral microorganisms. J Ethnopharmacol 119:473-477.

Omolo MO, Okinyo D, Ndiege IO et al. (2004) Repellency of essential oils of some Kenyan plants against Anopheles gambiae. Phytochemistry 65:2797-2802.

Palombo EA (2011) Traditional medicinal plant extracts and natural products with activity against oral bacteria: potential application in the prevention and treatment of oral diseases. Evid Based Complement Altern Med DOI: 10.1093/ecam/nep067.

Peter W, Deogracious O (2006) The in vitro ascaricidal activity of selected indigenous medicinal plants used in ethnoveterinary practices in Uganda. Afr J Tradit Complem 3:94-103.

Phillipson PB, Steyn CF (2008) Tetradenia (Lamiaceae) in Africa: new species and new combinations. Adansonia 30:177-196.

Porto TS, Rangel R, Furtado N et al. (2009) Pimarane-type diterpenes: antimicrobial activity against oral pathogens. Molecules 14:191-199.

Rios JL, Recio MC (2005) Medicinal plants and antimicrobial activity. J Ethnopharmacol 100:80-84.

Saleem M, Nazir M, Ali MS et al. (2010) Antimicrobial natural products: an update on future antibiotic drug candidates. Nat Prod Rep 27:238-254.

Scott G, Springfield EP, Coldrey N (2004) A pharmacognostical study of 26 South African plant species used as traditional medicines. Pharm Biol 42:186-213.

Sharma N, Charges CH, Lynch MC et al. (2004) Adjunctive benefit of an essential oil-containing mouthrinse in reducing plaque and gingivitis in patients who brush and floss regularly. J Am Dent Assoc 135:496-504.

Vanpuyvelde L, Dekimpe N, Ayobangira FX et al. (1988) Wheat rootlet growth-inhibition test of Rwandese medicinal plants: active principles of Tetradenia riparia and Diplolophium africanum. J Ethnopharmacol 24:233-246.

Vlietinck AJ, Van Hoof L, Tott J et al. (1995) Screening of hundred Rwandese medicinal plants for antimicrobial and antiviral properties. J Ethnopharmacol 46:31-47.

Associate Editor: Nilton Erbet Lincopan Huenuman

All the content of the journal, except where otherwise noted, is licensed under a Creative Commons License CC BY-NC. 